\title{
NÍVEIS PERIFÉRICOS DE TESTOSTERONA TOTAL EM TOUROS GUZERÁ
}

\author{
Juliano CeSAR Dias ${ }^{1}$, Venício José de ANDRAdE ${ }^{2}$, LuCAS LuZ EMERICK ${ }^{3}$, JORGE ANDRÉ MATIAS \\ MARTINS $^{3}$, VICENTE RIBEIRO DO VALE FILHO ${ }^{2}$
}

${ }^{1}$ Professor Doutor da Universidade Federal da Fronteira Sul, Laranjeiras do Sul, PR, Brasil. julianocdias@yahoo.com.br

${ }^{2}$ Professores Doutores da Universidade Federal de Minas Gerais, Belo Horizonte, MG, Brasil.

${ }^{3}$ Pós-Graduandos da Universidade Federal de Minas Gerais, Belo Horizonte, MG, Brasil

Foram avaliados 24 touros da raça Guzerá, de 24 a 34 meses de idade, com o objetivo de estudar o perfil da concentração sérica de testosterona e sua variação relativa à idade, peso corporal e características andrológicas. A concentração média de testosterona foi de $1,36 \mathrm{ng} / \mathrm{mL}$, com influência do horário de coleta nos níveis circulantes. A equação de regressão da concentração sérica de testosterona em função do peso corporal dos animais apresentou efeito linear, sugerindo que, para cada quilograma a mais no peso corporal, ocorre acréscimo de $0,0082 \mathrm{ng} / \mathrm{mL}$ nas concentrações de testosterona. A regressão da concentração sérica de testosterona e a circunferência escrotal (CE) também apresentou efeito linear indicando que, para cada centímetro a mais na $\mathrm{CE}$ nos touros Guzerá, ocorreu aumento de 0,2319 ng/mL na concentração de testosterona. A regressão da concentração espermática do sêmen em função da concentração sérica de testosterona apresentou efeito linear, os resultados mostram que, para cada $0,1 \mathrm{ng} / \mathrm{mL}$ a mais na concentração de testosterona circulante, ocorreu aumento de 9,29 × $10^{6}$ espermatozoides/mL de sêmen. Os resultados indicam que os níveis circulantes de testosterona podem auxiliar na identificação e seleção de touros Guzerá, com maior potencial reprodutivo.

PALAVRAS-CHAVE: andrologia; Guzerá; sêmen; testosterona; zebu.

\section{PERIPHERAL LEVELS OF TOTAL TESTOSTERONE IN GUZERAT BULLS}

\section{ABSTRACT}

Twenty-four Guzerat bulls were evaluated from 24 to 34 months of age, aiming to determinate the bulls serum testosterone concentration profile and their variation according to age, body weight and andrologic traits. The average of testosterone concentration was $1.36 \mathrm{ng} / \mathrm{mL}$, with effect of time at harvest on circulating levels. The regression equation of testosterone according to body weight showed linear effect, suggesting that for each kilogram added to the body weight, an increase of 0.0082 $\mathrm{ng} / \mathrm{mL}$ on serum testosterone concentrations occurs; and the regression of testosterone according to scrotal circumference (SC) also showed a linear effect. The results show that for each centimeter added to $\mathrm{SC}$ in Guzerat bulls, an increase of $0.2319 \mathrm{ng} / \mathrm{mL}$ on testosterone concentrations occurs. The regression of sperm concentration according to serum testosterone showed a linear effect, the results show that for each 0.1 $\mathrm{ng} / \mathrm{mL}$ added to serum testosterone concentration, an increase of $9.29 \times 10^{6}$ spermatozoa $/ \mathrm{mL}$ of semen occurs. The results indicate that circulating levels of testosterone may help on identification and selection of Guzerat bulls with major reproductive potential.

KEYWORDS: andrology; Guzerat; semen; testosterone; zebu. 


\section{INTRODUÇÃO}

A avaliação da capacidade reprodutiva do touro é de fundamental importância para a eficiência do rebanho, uma vez que, em função da representatividade numérica na usual relação touro:vaca, eles são responsáveis pela cobrição de grande número de fêmeas, transmitindo suas características genéticas a um grande número de descendentes podendo, desta forma, interferir na fertilidade e qualidade do rebanho. Neste sentido, é necessário considerar alguns fatores ligados à reprodução como: nutrição, condição corporal, desenvolvimento testicular, produção, viabilidade espermática, libido e outros parâmetros que comprometem a fertilidade do reprodutor (1-6).

A endocrinologia da reprodução envolve bioquímica, fisiologia, farmacologia e biologia molecular dos hormônios e seus receptores. Os hormônios sintetizados e secretados pelas glândulas endócrinas são transportados pela circulação sanguínea para estimular, inibir ou interagir com a atividade funcional ou órgão-alvo específicos produzindo grande variabilidade de respostas fisiológicas.

Os níveis circulantes de testosterona em machos bovinos têm sido estudados em várias fases do desenvolvimento dos animais, com variações na metodologia e nos objetivos dos trabalhos $(7,2,3,5-11)$. Correlações têm evidenciado associações favoráveis entre os níveis periféricos de testosterona, a fertilidade e a motilidade espermática. Post \& Christensen (12) constataram maiores taxas de fertilidade, verificadas pelo índice de prenhez de fêmeas, em touros com maiores concentrações de testosterona; entretanto, Andersson (7) encontrou correlação positiva entre a concentração de testosterona e a fertilidade de touros, avaliada pela taxa de não retorno, e a associação favorável entre a motilidade espermática e os níveis de testosterona. As relações entre os níveis circulantes de testosterona e a qualidade seminal em touros foram estudadas, apesar de ser dada pouca ênfase aos animais zebuínos.

Desta forma, o objetivo deste estudo foi avaliar o perfil da concentração sérica de testosterona e sua variação relativa à idade, ao peso corporal e às características andrológicas em touros da raça Guzerá.

\section{MATERIAL E MÉTODOS}

O trabalho foi desenvolvido na Fazenda Palestina, município de Unaí, noroeste do estado de Minas Gerais, tendo como coordenadas geográficas $16^{\circ} 35^{\prime} \mathrm{S}$ de latitude e $46^{\circ} 47^{\prime} \mathrm{W}$ de longitude, situada em área de Cerrado.

Foram avaliados o peso corporal, a circunferência escrotal (CE) e os aspectos físicos e morfológicos do sêmen (13) de 24 touros da raça Guzerá, com idade variando de 24 a 34 meses. Posteriormente, os animais foram submetidos à classificação andrológica por pontos (CAP), segundo Vale Filho (13).

As medições de circunferência escrotal (CE) foram obtidas por meio de fita métrica posicionada na região de maior diâmetro da bolsa escrotal. Quanto ao sêmen, foram avaliados os aspectos físicos (volume seminal, motilidade, vigor e concentração espermática) e morfológicos, classificados em defeitos maiores (DM), menores (Dm) e totais (DT).

As colheitas de sêmen foram realizadas com auxílio do aparelho de eletroejaculação e as avaliações físicas do sêmen realizadas imediatamente após as colheitas sob microscopia óptica. Para a avaliação morfológica, o sêmen foi fixado em solução de formol salina tamponada e transportado em temperatura ambiente até os laboratórios de andrologia da Escola de Veterinária da Universidade Federal de Minas Gerais, onde a análise foi realizada pela contagem de 200 células espermáticas em preparação úmida sob microscopia óptica de contraste de fase (14).

Para a determinação da concentração espermática, diluiu-se uma alíquota de sêmen em solução de formol salina tamponada (1:200), com posterior contagem em câmara hematimétrica (Neubauer) sob microscopia óptica.

Para a avaliação das concentrações séricas de testosterona, os animais foram submetidos a coletas de sangue, por punção da veia jugular, utilizando-se o sistema de coleta a vácuo, em tubos de vidro de cinco mililitros, sem anticoagulante. As coletas de sangue foram realizadas a cada duas horas, por um período de 12 horas (07:00, 09:00, 11:00, 13:00, 15:00, 17:00 e 19:00 horas).

Para a coleta de sangue, os animais foram divididos em dois grupos, com 12 animais cada, sendo as coletas iniciadas sempre pelo mesmo 
grupo, para que os intervalos de coleta se mantivessem dentro de uma mesma faixa de tempo.

Imediatamente após a coleta, a amostra de sangue era colocada em banho-maria a $4{ }^{\circ} \mathrm{C}$ por, aproximadamente, $\quad 30$ minutos, sendo posteriormente centrifugada a $3500 \mathrm{rpm}$ por 20 minutos. O soro sanguíneo, obtido após a centrifugação, era transferido para tubos criogênicos esterilizados, devidamente identificados, e colocados sob refrigeração a - 20 ${ }^{\circ} \mathrm{C}$, para posterior armazenamento em nitrogênio líquido $\left(-196^{\circ} \mathrm{C}\right)$, até o momento da análise.

A dosagem quantitativa das concentrações séricas de testosterona foi realizada em radioimunoensaio de fase sólida pelo método direto, cujo princípio baseia-se na competição entre antígenos dos padrões e das amostras com quantidade constante de antígeno marcado como traçador $\left({ }^{125} \mathrm{I}\right)$, para os sítios de ligação específicos dos anticorpos. A quantidade de antígeno não radioativo (testosterona) da amostra a se dosar é inversamente proporcional à quantidade de antígeno marcado. O complexo antígeno anticorpo é precipitado para separar a forma ligada da forma livre, procedendo posteriormente à contagem em contador gama; com determinação de uma curva padrão e a obtenção dos resultados expressos em nano gramas por mililitro de soro sanguíneo.

As análises das concentrações séricas de testosterona foram realizadas no Laboratório de Endocrinologia e Metabolismo do Instituto de Ciências Biológicas da Universidade Federal de
Minas Gerais, utilizando-se kits comerciais (Testosterona Total COAT-A-COUNT® - DPC Diagnostic Products Corporation, Los Angeles, Califórnia, USA.).

Para a análise dos dados referentes aos níveis de testosterona, realizou-se a transformação logarítmica $(X+1)$. Para a observação do efeito das concentrações de testosterona sobre as características físicas e morfológicas do sêmen e classificação andrológica por pontos (CAP), compararam-se animais com concentrações de testosterona acima e abaixo da média geral do grupo, utilizando-se o teste de SNK com 5\% de probabilidade e recursos do pacote estatístico SAS (15).

Foram também calculados os coeficientes de regressão da testosterona em função do horário da coleta, idade, peso corporal e circunferência escrotal e, ainda, o coeficiente de regressão da concentração espermática em função da testosterona.

\section{RESULTADOS E DISCUSSÃO}

Na Tabela 1 são apresentadas as médias e desvios-padrão da idade, peso corporal, circunferência escrotal, características seminais e CAP de touros jovens da raça Guzerá. Os dados são próximos daqueles descritos na literatura para touros Guzerá na mesma faixa etária $(10,22)$, situando-se dentro do padrão descrito para touros zebuínos $(13,3,18)$.

Tabela 1 - Médias e desvios-padrão da idade, peso corporal, características físicas e morfológicas do sêmen e classificação andrológica por pontos (CAP) de touros jovens da raça Guzerá

\begin{tabular}{|c|c|c|c|c|c|c|c|c|c|c|}
\hline $\begin{array}{l}\text { Idade } \\
\text { (meses) }\end{array}$ & $\begin{array}{l}\text { Peso } \\
(\mathrm{Kg})\end{array}$ & $\begin{array}{l}\mathrm{CE} \\
(\mathrm{cm})\end{array}$ & $\begin{array}{l}\text { Mot } \\
(\%)\end{array}$ & $\begin{array}{l}\text { Vigor } \\
(0-5)\end{array}$ & $\begin{array}{l}\text { DM } \\
(\%)\end{array}$ & $\begin{array}{l}\mathrm{Dm} \\
(\%)\end{array}$ & $\begin{array}{l}\text { DT } \\
(\%)\end{array}$ & $\begin{array}{l}\text { Vol } \\
(\mathrm{mL})\end{array}$ & $\begin{array}{c}\text { Conc } \\
\left(\times 10^{6} \mathrm{sptz} / \mathrm{mL}\right)\end{array}$ & $\begin{array}{c}\text { CAP } \\
(0-100)\end{array}$ \\
\hline
\end{tabular}

$29,4 \pm 3,2 \quad 464,1 \pm 99,5 \quad 32,3 \pm 2,7 \quad 60,2 \pm 7,3 \quad 4,2 \pm 0,7 \quad 7,5 \pm 4,2 \quad 12,1 \pm 5,5 \quad 19,6 \pm 6,4 \quad 9,1 \pm 1,5 \quad 284,5 \pm 147,1 \quad 70,7 \pm 15,1$

OBS: Peso = peso corporal; $\mathrm{CE}=$ circunferência escrotal; $\mathrm{Mot}=$ motilidade espermática; Vigor $=$ vigor espermático; $\mathrm{DM}=$ defeitos espermáticos maiores; Dm = defeitos espermáticos menores; DT = defeitos espermáticos totais; Vol = volume de sêmen; Conc = concentração espermática; CAP = classificação andrológica por pontos.

As amplitudes de variações das secreções de testosterona no soro sanguíneo oscilaram desde níveis inferiores a $0,02 \mathrm{ng} / \mathrm{mL}$ até $12,84 \mathrm{ng} / \mathrm{mL}$; com média e desvio-padrão de $1,36 \pm 1,12 \mathrm{ng} / \mathrm{mL}$. Essa variação pode ser explicada pelo padrão circadiano de liberação da testosterona apresentado pelos bovinos (6).
A equação de regressão da concentração sérica de testosterona em função do horário de coleta $\left(\hat{Y}=668,8117^{*} X^{-2,8922}, \quad \mathrm{p}<0,0001, \quad \mathrm{R}^{2}=0,39\right)$ apresentou efeito geométrico, sugerindo que, das sete às dezenove horas, houve redução gradativa nos níveis circulantes deste hormônio, com queda de $0,184 \mathrm{ng} / \mathrm{mL}$ a cada hora (Figura 1 ). 


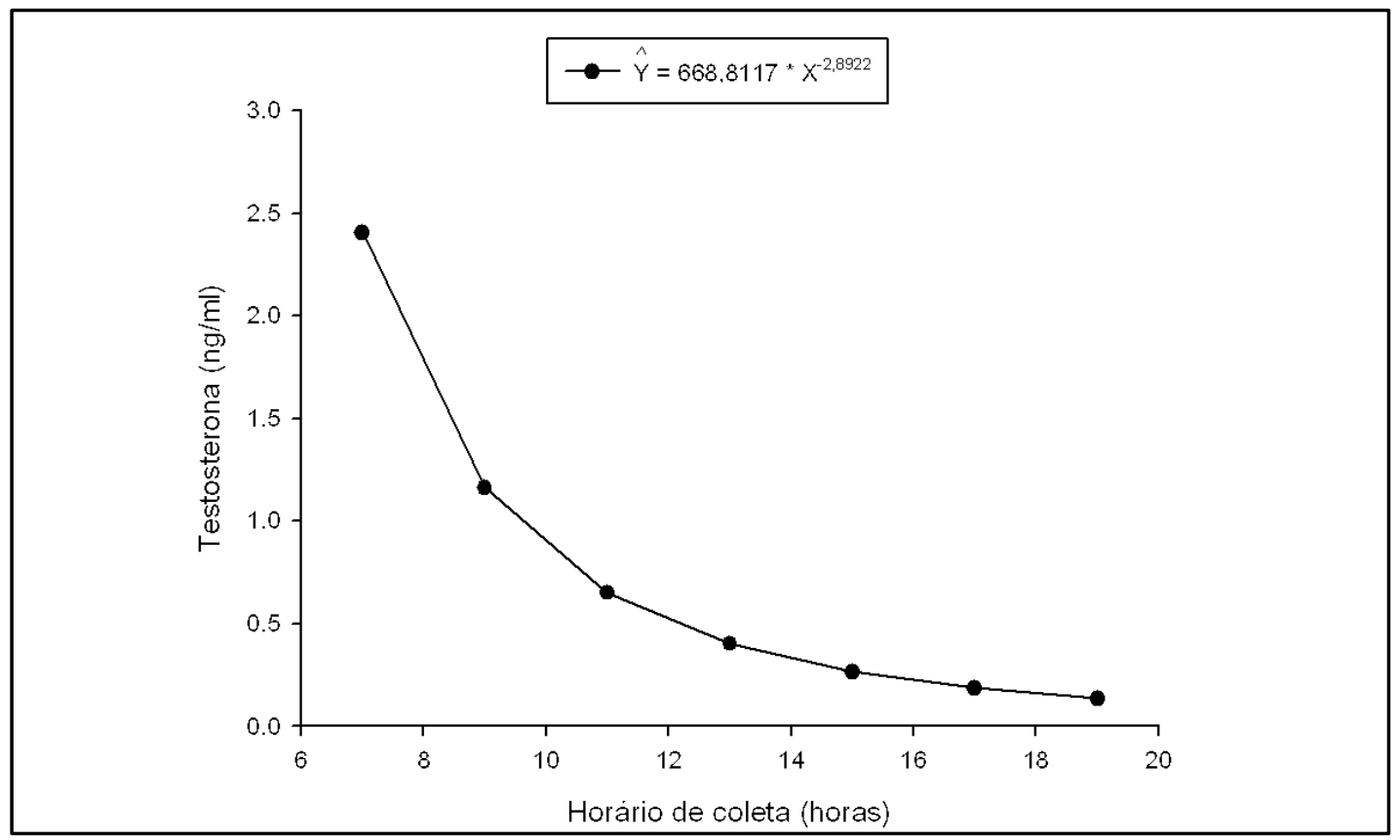

Figura 1 - Regressão das concentrações séricas de testosterona em função do horário de coleta em touros da raça Guzerá.

Pode-se observar maior queda entre sete e oito horas $(-0,77 \mathrm{ng} / \mathrm{mL})$, com os níveis basais de testosterona tendendo à estabilização na concentração circulante, a partir das 13 horas. A manutenção desses níveis é importante para a espermatogênese nos testículos, para a maturação dos espermatozoides nos epidídimos e para o desenvolvimento e funções dos órgãos sexuais acessórios masculinos (24).

Considerando que os dados disponíveis na literatura apresentam diferentes metodologias de avaliação da concentração de testosterona em bovinos, quanto ao intervalo e frequência de coleta, raça e idade dos animais, utilização ou não de hormônio liberador de gonadotrofinas (GnRH), métodos utilizados para análise e condições nutricionais a que os touros foram submetidos no período da coleta, pode-se conjecturar que as concentrações aqui obtidas estão dentro de uma faixa normal.

Para observação da associação das concentrações séricas de testosterona com idade, peso corporal, características seminais e classificação andrológica por pontos (CAP), compararam-se animais com concentrações de testosterona acima e abaixo da média geral do grupo (Tabela 2).

Tabela 2 - Médias e desvios-padrão da idade, peso corporal, características seminais e classificação andrológica por pontos (CAP) de touros jovens da raça Guzerá, com concentrações séricas de testosterona acima e abaixo da média $(1,36 \pm 1,12 \mathrm{ng} / \mathrm{mL})$

\begin{tabular}{|c|c|c|c|c|c|c|c|c|c|c|}
\hline $\begin{array}{c}\text { Testost } \\
(\mathrm{ng} / \mathrm{mL})\end{array}$ & $\mathrm{N}$ & $\begin{array}{c}\text { Idade } \\
\text { (meses) }\end{array}$ & $\begin{array}{l}\text { Peso } \\
(\mathrm{Kg})\end{array}$ & $\begin{array}{l}\mathrm{CE} \\
(\mathrm{cm})\end{array}$ & $\begin{array}{l}\text { Mot } \\
(\%)\end{array}$ & $\begin{array}{l}\mathrm{DM} \\
(\%) \\
\end{array}$ & $\begin{array}{l}\text { DT } \\
(\%)\end{array}$ & $\begin{array}{c}\text { Vol } \\
(\mathrm{mL})\end{array}$ & $\begin{array}{c}\text { Conc } \\
\left(\times 10^{6} \mathrm{sptz} / \mathrm{mL}\right)\end{array}$ & $\begin{array}{c}\text { CAP } \\
(0-100) \\
\end{array}$ \\
\hline $2,45 \pm 0,91$ & 10 & $31,2 \pm 1,9^{\mathrm{a}}$ & $525,0 \pm 122,9^{a}$ & $32,8 \pm 3,2^{\mathrm{a}}$ & $61,0 \pm 8,7^{\mathrm{a}}$ & $5,9 \pm 2,7^{\mathrm{a}}$ & $16,9 \pm 4,4^{\mathrm{a}}$ & $9,5 \pm 1,6^{\mathrm{a}}$ & $357,7 \pm 166,9^{\mathrm{a}}$ & $74,2 \pm 15,9^{\mathrm{a}}$ \\
\hline $0,57 \pm 0,29$ & 14 & $28,0 \pm 3,2^{b}$ & $420,5 \pm 46,3^{b}$ & $31,9 \pm 2,1^{\mathrm{a}}$ & $59,6 \pm 6,3^{\mathrm{a}}$ & $8,6 \pm 4,7^{\mathrm{a}}$ & $21,5 \pm 7,0^{\mathrm{a}}$ & $8,7 \pm 1,3^{\mathrm{a}}$ & $218,5 \pm 91,2^{\mathrm{a}}$ & $68,1 \pm 14,4^{\mathrm{a}}$ \\
\hline
\end{tabular}

Observou-se diferença $(\mathrm{p}<0,05)$ entre a idade nos animais com testosterona acima e abaixo da média. Avaliando-se o efeito da idade sobre a concentração de testosterona em touros da raça
Holandesa, de quatro e seis anos de idade, Katongole (23) verificou médias de 2,0 $\pm 0,15$ e 23,91 $\pm 0,36$ $\mathrm{ng} / \mathrm{mL}$, respectivamente, diferença essa altamente significativa. Amann \& Schanbacher 
mencionaram que o perfil da concentração de testosterona apresenta crescimento linear com o avanço da idade.

A equação de regressão da concentração sérica de testosterona em função da idade dos animais $\left(\hat{\mathrm{Y}}=0,00000012 * \mathrm{X}^{4,8042}, \mathrm{p}<0,01, \mathrm{R}^{2}=0,32\right)$ apresentou efeito geométrico, sugerindo aumento gradativo nos níveis circulantes deste hormônio, a medida em que os animais ficam mais velhos (Figura 2).

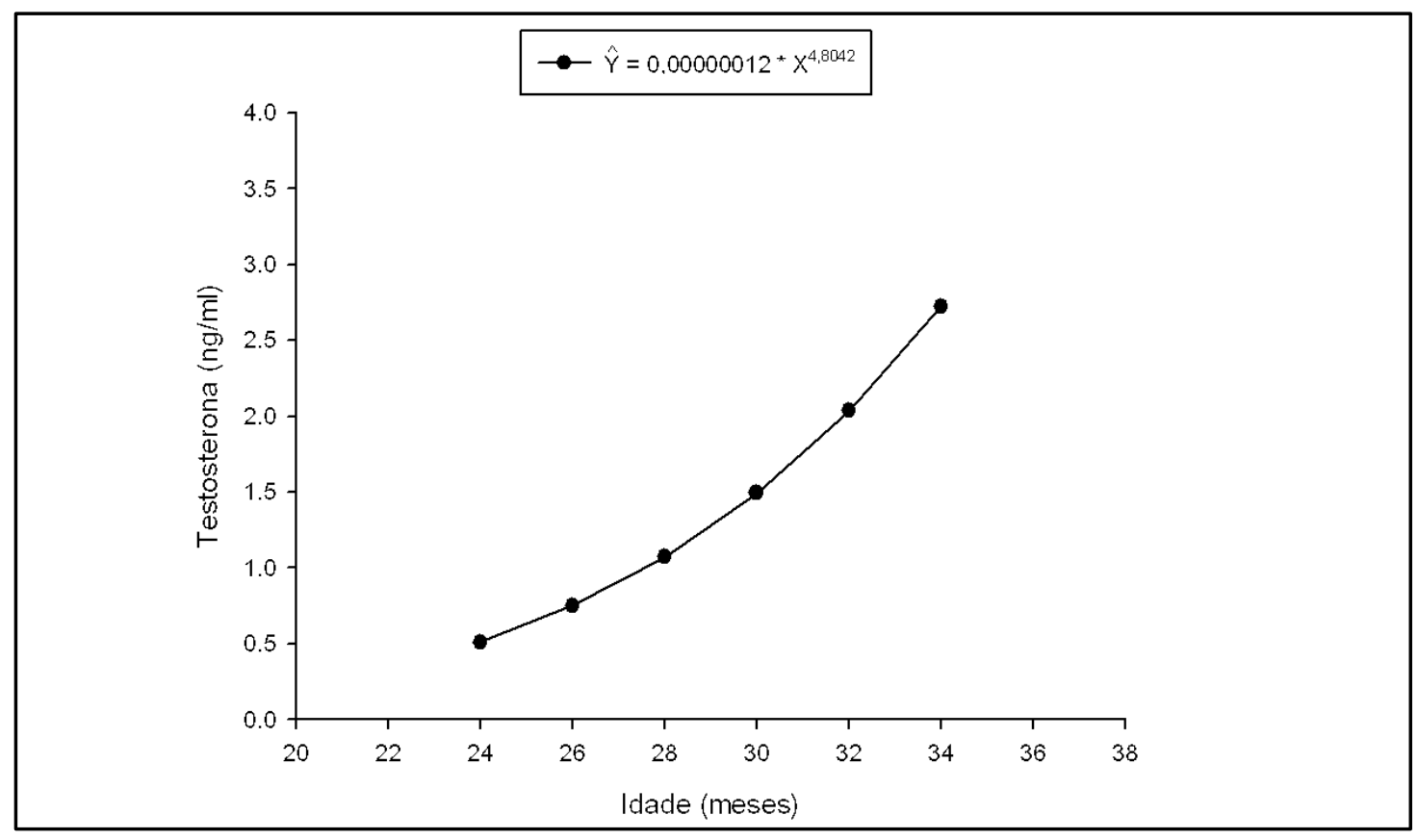

Figura 2 - Regressão das concentrações séricas de testosterona em função da idade em touros jovens da raça Guzerá.

Constatou-se que, para cada mês a mais na idade de touros Guzerá de 24 a 34 meses, ocorre acréscimo médio de $0,199 \mathrm{ng} / \mathrm{mL}$ nas concentrações séricas de testosterona; com o aumento máximo na concentração ocorrendo entre o $33^{\circ}$ e $34^{\circ}$ mês $(0,365$ $\mathrm{ng} / \mathrm{mL}$ ).

Segundo Aguiar et al. (11) e Assumpção et al. (25), a concentração de testosterona aumenta com a idade, proporcionando um pico entre sete e oito meses (26); com tendência a diminuir após este período, permanecendo estável até o início da puberdade, quando apresenta um novo aumento (11, 24).

Renaville et al. (27), Moura \& Ericksson (2) e Assumpção et al. (25) sugeriram que o aparecimento precoce do perfil da testosterona poderia ser indicativo do desenvolvimento testicular, do início da puberdade e da maturidade sexual dos machos, podendo, dessa forma, selecionar precocemente os animais que entrarão na reprodução.

Verificou-se, também, diferença $(\mathrm{p}<0,05)$ entre peso corporal nos animais com concentrações de testosterona acima e abaixo da média geral (Tab. 2). A equação de regressão da concentração sérica de testosterona em função do peso corporal dos animais $\left(\hat{Y}=-2,4404+0,0082 * X, \quad p<0,01, \quad R^{2}=0,52\right)$ apresentou efeito linear, sugerindo aumento constante nos níveis circulantes deste hormônio, na medida em que os animais ficam mais pesados (Figura 3). Os dados permitem afirmar que para cada quilograma a mais no peso corporal de touros Guzerá, de 24 a 34 meses, ocorre um acréscimo de $0,0082 \mathrm{ng} / \mathrm{mL}$ nas concentrações séricas de testosterona.

A associação do peso corporal e testosterona pode ser explicada pelos efeitos anabólicos deste hormônio, dentre os quais se destacam o aumento da massa muscular, concentração de hemoglobina, de hematócrito, retenção de nitrogênio, deposição de cálcio nos ossos e diminuição das reservas de gordura do corpo (20-21).

Dentre os mecanismos anabólicos desencadeados para aumento da massa muscular incluem-se: aumento da síntese proteica via RNA mensageiro, balanço nitrogenado positivo, inibição dos efeitos catabólicos da massa muscular esquelética, estimulação da formação de osso, inibição do catabolismo proteico e estímulo da eritropoiese. 


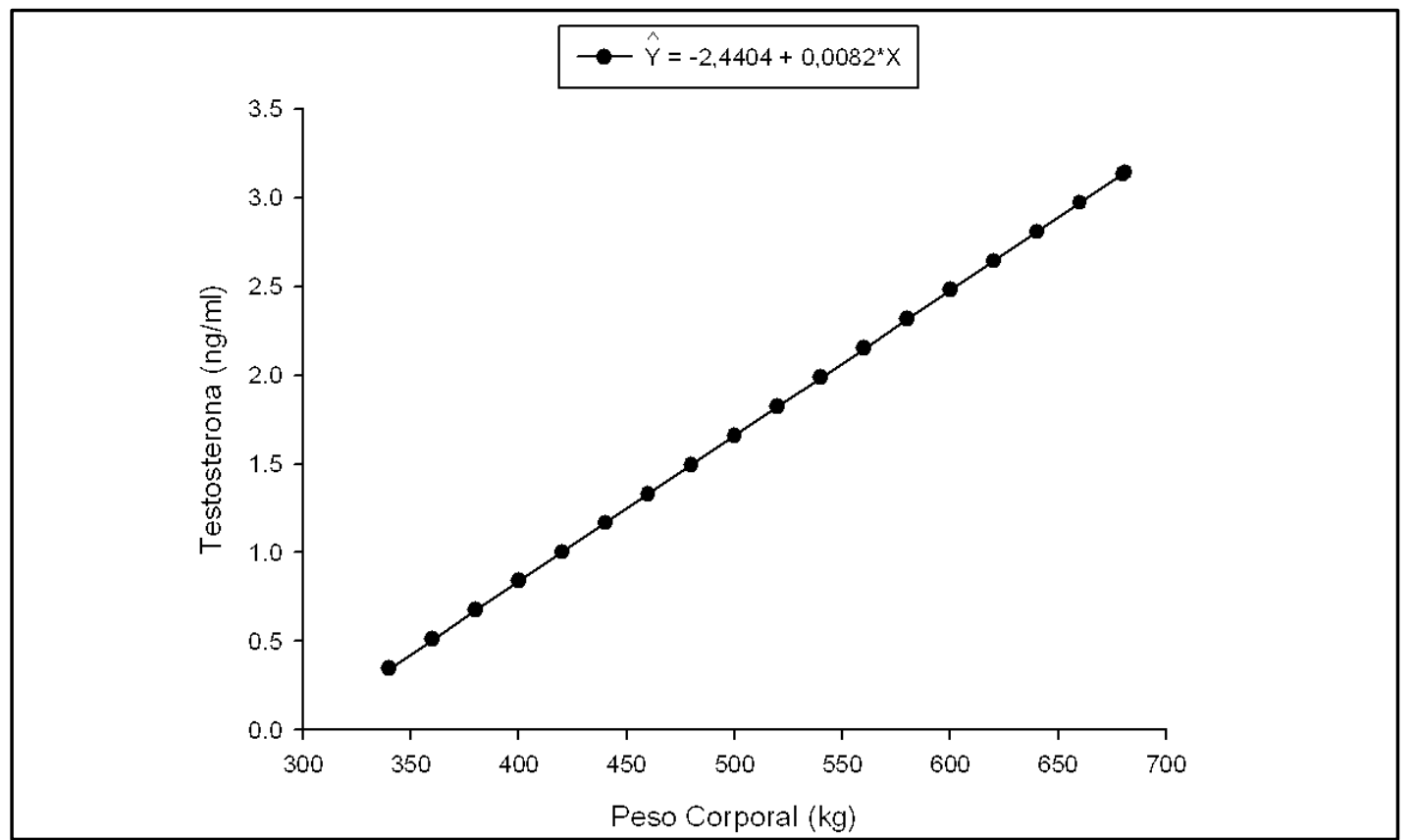

Figura 3 - Regressão das concentrações séricas de testosterona em função do peso corporal em touros jovens da raça Guzerá.

Os efeitos anabólicos ocasionam retenção de nitrogênio, um constituinte básico da proteína, promovendo, assim, crescimento e desenvolvimento de massa muscular pela melhor utilização da proteína ingerida (21).

Outra forma de explicar a associação entre a melhor condição corporal e as concentrações de testosterona pode ser encontrada nos resultados de Brito et al. (17), que observaram que a melhoria na nutrição dos animais resultou em aumento nas concentrações de testosterona, que foi associado com uma maior concentração do fator de crescimento semelhante à insulina - I (IGF - I), considerado importante mediador da ação metabólica e do estímulo ao crescimento, correlacionando-se positivamente com a taxa de ganho de peso vivo e eficiência alimentar $(9,30)$.

Reforçando esses achados, Brito et al. (1617) sugeriram que a nutrição afeta a esteroidogênese testicular por alterar o número e/ou a função das células de Leydig e que o aumento na concentração de testosterona relacionado à idade foi acelerado nos animais que receberam alta nutrição e atrasado nos animais sob restrição nutricional.

Para a verificação da possível associação da concentração sérica de testosterona e da circunferência escrotal, estabeleceram-se modelos de regressão (Figura 4). Observou-se efeito linear $(\hat{\mathrm{Y}}=$ $\left.6,144+0,2319^{*} X, p<0,01, R^{2}=0,30\right)$, sugerindo aumento constante na concentração de testosterona com o aumento da $\mathrm{CE}$, sem um limite máximo dentro da faixa etária avaliada. Os resultados mostram que, para cada centímetro a mais na CE nos touros Guzerá, ocorreu aumento de $0,2319 \mathrm{ng} / \mathrm{mL}$ na concentração sérica de testosterona.

Courot \& Ortovant (31) e Oliveira et al. (19) descreveram que o tamanho dos testículos está relacionado com as concentrações sanguíneas do hormônio folículo estimulante (FSH), LH e testosterona, encontrando efeito linear na relação entre o tamanho testicular e o nível circulante médio de LH e de testosterona.

Moura et al. (3) e Aguiar et al. (11) observaram que, quando ocorre elevação na síntese de testosterona na pré-puberdade, há também aumento considerável no diâmetro dos túbulos seminíferos, devido à multiplicação das células germinativas e diferenciação das células de Sertoli, com alteração no desenvolvimento das gônadas. Os autores verificaram, ainda, que, após a puberdade, houve crescimento contínuo das medidas testiculares e, como nesta fase não há mais proliferação das células de Sertoli, esse crescimento sugere aumento da população de células germinativas no interior dos túbulos seminíferos. Como essas células são testosterona dependentes, o aumento na CE pode ser explicado dessa forma, sugerindo a andrógenodependência da CE. 


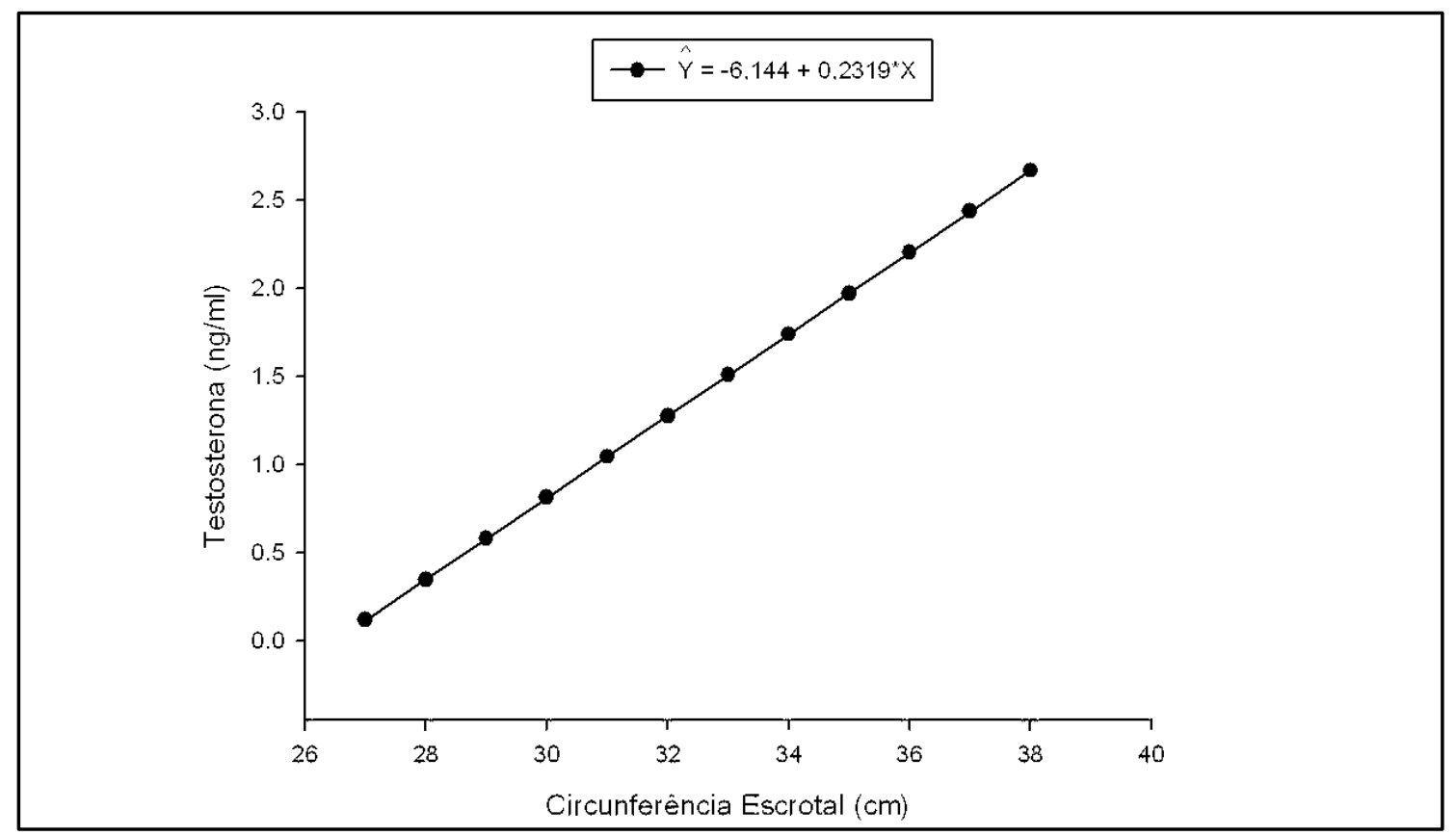

Figura 4 - Regressão das concentrações séricas de testosterona em função da circunferência escrotal em touros jovens da raça Guzerá.

Os achados de Brito et al. (16-17) reforçam esses resultados mostrando que a melhoria nutricional precoce resultou em maior peso testicular e produção de espermatozoides na maturidade, indicando que o aumento da secreção de LH e das concentrações de IGF-I e de testosterona durante os períodos de confinamento e peripuberal foram associadas a uma maior proliferação e aumento da função de células testiculares.

Martin et al. (29), estudando o efeito da nutrição no tamanho do testículo de carneiros, verificaram que os efeitos da dieta no crescimento testicular também envolve mecanismos que são independentes das mudanças na secreção de gonadotropinas e, consequentemente, de esteroides gonadais.

Para a verificação da possível associação da concentração sérica de testosterona e a concentração espermática do sêmen, foram estabelecido modelos de regressão, sendo observado efeito linear $(\hat{\mathrm{Y}}=$ $\left.143,2567+92,703 * X, p<0,01, R^{2}=0,55\right)$, sugerindo aumento constante na produção espermática com o aumento da concentração circulante de testosterona (Figura 5). Os resultados mostram que, para cada 0,1 $\mathrm{ng} / \mathrm{mL}$ a mais na concentração média de testosterona circulante em touros da raça Guzerá, de 24 a 34 meses de idade, ocorreu aumento de 9,29 × $10^{6}$ espermatozoides $/ \mathrm{mL}$ de sêmen.

Amann (32) e Amann \& Schanbacher (24) afirmam que a produção espermática diária aumenta por determinado tempo após a puberdade, podendo variar com a estação do ano, e entre animais de uma determinada raça ou espécie, devido a diferenças no tamanho dos testículos.

A elevação nos níveis basais de testosterona é consequência da diferenciação das células de Leydig e está associada à proliferação das células germinativas, eventos essenciais para a puberdade (24). O processo de multiplicação, meiose e diferenciação das células germinativas em estádios mais avançados de desenvolvimento está sincronizado com as mudanças morfológicas, a expressão gênica nas células de Sertoli e Leydig e as secreções hormonais.

As gonadotropinas (FSH e LH) controlam a proliferação e diferenciação das células de Sertoli e Leydig desde a fase pós-natal, de modo que os esteroides e fatores de crescimento secretados por essas células têm ação direta ou indireta sobre o desenvolvimento das células germinativas (4, 8-11). As ações direta e indireta da testosterona na multiplicação e diferenciação das células germinativas, que irão originar os espermatozoides durante o processo da gametogênese, podem ser a explicação da associação desse hormônio com a concentração espermática nos touros já maturos sexualmente. 


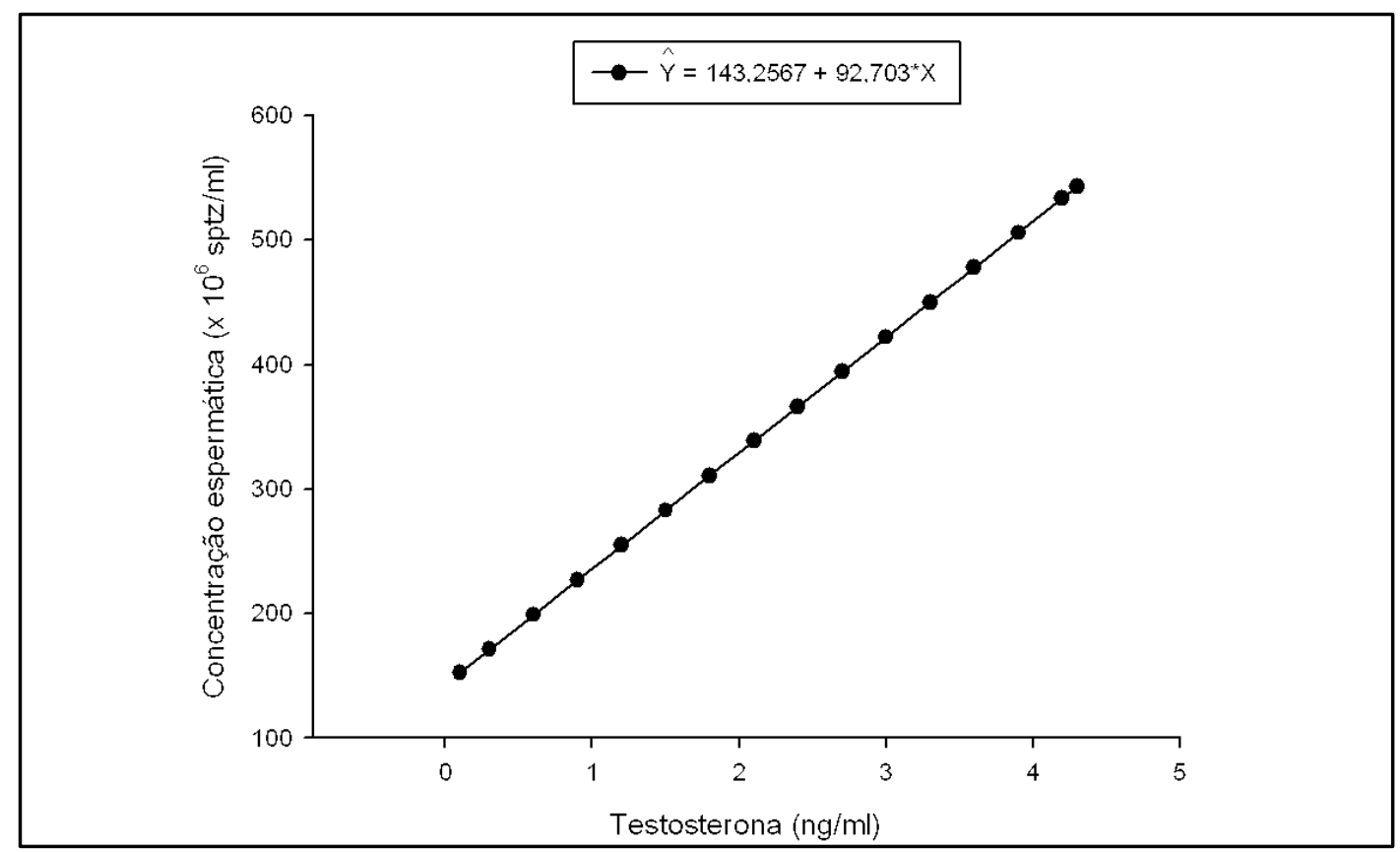

Figura 5 - Regressão da concentração espermática do sêmen em função da concentração sérica de testosterona em touros jovens da raça Guzerá.

Courot \& Ortavant (31) verificaram, em carneiros, que a espermatogênese é sensível às variações nos níveis de hormônios circulantes, existindo correlação positiva entre o número, a renovação ou a eficiência da multiplicação das espermatogônias e as concentrações de LH no sangue periférico de carneiros adulto. Os autores verificaram, ainda, que a testosterona tem efeito no início do ciclo da espermatogênese e, quantitativamente, mantém a meiose e a espermiogênese, mas a diferenciação das espermátides é dependente da informação armazenada no início da meiose e requer a ação da testosterona e de outros fatores.

Abdel Malak \& Thibier (28) concluíram que assim que os processos fisiológicos da espermatogênese são iniciados e controlados pelas secreções hormonais, as variações qualitativas e quantitativas do sêmen são independentes das flutuações espontâneas da testosterona, o que concorda parcialmente com os dados encontrados neste estudo.

\section{CONCLUSÕES}

A concentração sérica de testosterona aumenta com a idade, peso corporal e circunferência escrotal, podendo ser um parâmetro para auxiliar na identificação e seleção de touros jovens da raça Guzerá, com maior potencial reprodutivo.

\section{AGRADECIMENTOS}

À Fundação de Amparo à Pesquisa do Estado de Minas Gerais - FAPEMIG, pelo financiamento da pesquisa. Ao Sr. Paulo Emílio de A. Carneiro, proprietário da fazenda Palestina, pela contribuição na realização deste trabalho.

\section{REFERÊNCIAS}

1. Santos MD, Torres CAA, Ruas JRM, Machado GV, Costa DS, Angulo LM. Concentrações séricas de testosterona em touros zebu. Revista Brasileira de Zootecnia. 2000;39(3):738-744.

2. Moura AA, Ericksson BH. Testicular development, histology, and hormone profiles in three yearling angus bulls with spermatogenic arrest. Theriogenology. 2001;55(7):1469-1488.

3. Moura AAA, Rodrigues GC, Martins Filho R. Desenvolvimento ponderal e testicular, concentrações periféricas de testosterona e características de abate em touros da raça Nelore. Revista Brasileira de Zootecnia. 2002;31(2 Supl):934-943.

4. Anway MD, Li Y, Ravindranath N, Dym M, Griswold M. Expression of testicular germ cell genes identified by differential display analysis. Journal of Andrology. 2003;24(2):173-184.

5. Jiménez-Severiano H, Quintal-Franco J, Veja-Murillo V, Zanela E, Wehrman ME, Lindsey BR, Melvin EJ, Kinder JE. Season of the year influences testosterone secretion in bulls administered luteinizing hormone. Journal of Animal Science. 2003;81(4):1023-1029.

6. Santos MD, Torres CAA, Guimarães JD, Ruas JRM, 
Carvalho GR. Libido de touros Nelore: efeito da proporção touro: vaca sobre a taxa de gestação. Arquivo Brasileiro de Medicina Veterinária e Zootecnia. 2003;55(3):293-300.

7. Andersson M. Relationship between GnRH-induced testosterone máxima, sperm motility and fertility in Ayrshire bulls. Animal Reproduction Science. 1992;27(23):107-111.

8. Walker WH. Molecular mechanisms controlling Sertoli cell proliferation and differentiation. Endocrinology. 2003;144(9):3719-3721.

9. Cervieri RC, Arrigoni MB, Chardulo LAL, Silveira AC, Oliveira HN, Martins CL. Peso vivo final, ganho de peso, características de carcaça e concentrações plasmáticas de IGF-I e hormônios tireoideanos de bezerros mestiços Angus-Nelore recebendo somatotropina bovina recombinante (rbST) até a desmama. Revista Brasileira de Zootecnia. 2005;34(6):2009-2019.

10. Torres-Júnior JRS, Henry M. Sexual development of Guzerat (Bos taurus indicus) bulls raised in a tropical region. Animal Reproduction. 2005;2(2):114-121.

11. Aguiar GV, Araújo AA, Moura AAA. Desenvolvimento testicular, espermatogênese e concentrações hormonais em touros Angus. Revista Brasileira de Zootecnia. 2006;35(4 Supl):1629-1638.

12. Post TB, Christensen HR. Testosterone variability and fertility in bulls. Theriogenology. 1976;6(6):615-616.

13. Vale Filho VR. Andrologia no touro: avaliação genital, exame do sêmen e classificação por pontos. Revista Brasileira de Reprodução Animal. 1997;21(3):713.

14. Arruda RP, Celeghini ECC, Alonso MA, Carvalho HF, Oliveira LZ, Nascimento J, Silva DF, Affonso FJ, Lemes KM, Jaimes JD. Métodos de avaliação da morfologia e função espermática: momento atual e desafios futuros. Revista Brasileira de Reprodução Animal. 2011;35(2):145-151.

15. SAS Institute. Analysis System: user guide [CDROM]. Cary (NC): SAS Insitute Inc., 1996.

16. Brito LFC, Barth AD. Rawlings NC, Wilde RE, Crews JRDH, Boisclair YR, Ehrhardt RA, Kastelic JP. Effect of feed restriction during calfhood on serum concentrations of metabolic hormones, gonadotropins, testosterone, and on sexual development in bulls. Reproduction. 2007;134(1):171-181.

17. Brito LFC, Barth AD, Rawlings NC, Wilde RE, Crews JRDH, Mir PS, Kastelic JP. Effect of improved nutrition during calfhood on serum metabolic hormones, gonadotropins, and testosterone concentrations, and on testicular development in bulls. Domestic Animal Endocrinology. 2007;33(4):460-469.

18. Vale Filho VR, Andrade VJ, Ferreira MBD, Azevedo NA. Aspectos andrológicos de touros da raça Gir. Informe Agropecuário. 2008;29(243):125-131.
19. Oliveira LZ, Oliveira C., Monteiro FM, Lima VFMH, Lima FM, Costa MZ. Efeito da idade sobre as principais características andrológicas de touros Brangus-Ibagé criados extensivamente no estado do Mato Grosso do Sul - Brasil [Effect of age on the andrological characteristics of Brangus-Ibagé bulls extensively reared in Mato Grosso do Sul state - Brazil]. Acta Scientiae Veterinariae [Internet]. 2011 [cited 2013 Nov 08];39(1):946. Available from: http://www.ufrgs.br/actavet/39-1/PUB\%20946.pdf. Portuguese.

20. Zhou ZK, Gao X, Li J, Chen JB, Xu SZ. Effect of castration on carcass quality and differential gene expression of longissimus muscle between steer and bull. Molecular Biology Reports. 2011;38(8):5307-5312.

21. Faria PP, Oliveira CGA, Souza AD, Benedito MG, Thomé MPM. Avaliação de parâmetros físicos e biológicos de ratos wistar após administração de decanoato de nandrolona. Acta Biomedica Brasiliensia. 2012;3(2):26-37.

22. Osorio JP, Henry M, Bergmann JAG, Carmo AS, Souza FA. Desenvolvimento testicular e puberdade em machos da raça guzerá da desmama aos 36 meses de idade criados no cerrado mineiro. Revista de Medicina Veterinaria. 2012;24:9-24.

23. Katongole CB. A competitive protein - binding assay for testosterone in the plasma of bull and ram. Journal of Endocrinology. 1971;51(2):303-312.

24. Amann RP, Schanbacher BD. Physiology of male reproduction. Journal of Animal Science. 1983;57(2):380403.

25. Assumpção TI, Souza MA, Alberton C, Pallaoro R, Kitagawa C, Silva NAM. Características reprodutivas de machos bovinos da raça Nelore da fase pré-púbere à maturidade sexual. Revista Brasileira de Ciência Veterinária. 2013;20(3):148-154.

26. Sundby A, Velle W. Plasma concentration of testosterone in young bulls in relation to age, rate of weight gain and stimulation with human chorionic gonadotrophin. Journal of Endocrinology. 1980 Sep;86(3):465-9.

27. Renaville R, Fabry J, Halleux V, Burny A. Testosterone plasma profile, as a function of age in young bulls from the bovine double-muscled Belgian White Blue Bred. A preliminar report. Theriogenology. 1983;19(2):159-167.

28. Abdel Malak G., Thibier M. Lack of between spontaneous fluctuations of $\mathrm{FSH}, \mathrm{LH}$ and testosterone and semen output quality in young postpubertal bulls. Zuchthygiene. 1985;20(5):222-228.

29. Martin GB, Tjondronegoro S, Blackberry MA. Effects of nutrition on testicular size and the concentrations of gonadotrophins, testosterone and inhibin in plasma of mature male sheep. Journal of Reproduction and Fertilty. 1994;101(1):121-128.

30. Stick DA, Davis ME, Loerch SC, Simmen CM. 
Relationship between blood serum insulin-like growth spermatogenesis in the ram. Journal of Reproduction and factor I concentration and postweaning feed efficiency of Fertility. Supplement. 1981;30:47-60.

crossbred cattle at three levels of dietary intake. Journal of Animal Science. 1998;76(2):498-505.

32. Amann RP. Endocrine changes associated with onset 31. Courot M, Ortavant R. Endocrine control of Science. 1983;66(12):2606-2622.

Protocolado em: 11 nov. 2008. Aceito em: 13 nov. 2013. 